\title{
Clinical conundrums in management of sepsis in the elderly
}

\author{
Vishal Sehgal $^{1}$, Sukhminder Jit Singh Bajwa ${ }^{2}$, John A. Consalvo ${ }^{3}$, Anurag Bajaj ${ }^{4}$ \\ 'Department of Internal Medicine, The Common Wealth Medical College, Scranton, PA 18510, USA; \\ ${ }^{2}$ Department of Anaesthesiology and Intensive Care Medicine, Gian Sagar Medical College, Banur, Patiala, \\ Punjab, India; \\ ${ }^{3}$ Chairman Emergency Medicine, Regional hospital of Scranton, PA, USA; \\ ${ }^{4}$ Department of Internal Medicine, WCGME, SCRANTON, PA, USA
}

Address for Correspondence: Dr. Vishal sehgal, 920 Madison Avenue Suite 300A

Memphis, Tennessee 38163, USA

Email: vsehgal@uthsc.edu

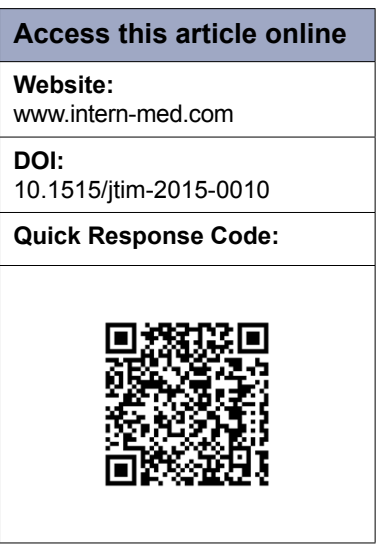

\section{ABSTRACT}

In 2012, surviving sepsis campaign came out with updated international guidelines for management of severe sepsis and septic shock. Paradoxically, there are no specific guidelines for management of sepsis in the elderly, although the elderly are more predisposed to sepsis, and morbidity and mortality related to sepsis. Sepsis in the elderly is, more often than not, complicated by clinical conundrums such as congestive heart failure (CHF), atrial fibrillation (AF), chronic kidney disease (CKD), acute kidney injury (AKI), delirium, dementia, ambulatory dysfunction, polypharmacy, malglycemia, nutritional deficiencies, and antibiotic resistance. Also, with recurrent admissions to the hospital and widespread use of antibiotics, the elderly are more susceptible to Clostridium difficile colitis.

Key words: sepsis, atrial fibrillation, congestive heart failure, malglycemia, elderly, chronic kidney disease, antibiotic resistance

In 2003, surviving sepsis campaign gave a precise definition for sepsis ${ }^{[1]}$. Diagnostic criteria for sepsis in the elderly is the same as applied to general population. This includes documented or suspected infection plus change in any hemodynamic or hematological variable. These may include change in vitals including temperature, respiratory rate, blood pressure, and tachycardia. Markers of cellular immunity may be altered that may manifest as increased white blood cells (WBCs), decreased WBCs, increased C-reactive protein, or increased procalcitonin (PCT) level. There may be signs of organ dysfunction that may manifest as hypoxia, renal dysfunction, ileus, increased cardiac index, and hyperbilirubinemia. There may be signs of decreased tissue perfusion that may manifest as increased lactate or ileus. Severe sepsis refers to sepsis with organ dysfunction requiring support. Thus, the term sepsis and severe sepsis are often used interchangeably. Septic shock is defined as sepsis-induced hypotension or hyperlactatemia persisting despite adequate fluid resuscitation. Multiple organ dysfunction syndrome (MODS) refers to progressive organ dysfunction in an acutely ill patient needing critical care support.

\section{METHODS OF LITERATURE SEARCH}

The review was performed after searching the full text and abstracts from the literature in Pubmed, HINARI, Scopus, Science Direct, Ovid MEDLINE, and Google scholar and the following keywords combinations were used: Sepsis, CHF, elderly, CKD, Antibiotic resistance. Various text books of critical care medicine and anesthesiology as well as international anesthesia journals were also searched for full text articles related to management of sepsis in the elderly.

\section{EPIDEMIOLOGY: INCIDENCE AND RISK FACTORS}

The incidence of sepsis is disproportionately increased in older adult patients and age is an independent predictor of mortality due to 
sepsis ${ }^{[2]}$. The cytochrome (CYH) and p-gp system involved in drug metabolism also slows down with aging and could potentially accentuate drug toxicities and delirium seen in critical care settings ${ }^{[3,4]}$. Case fatality of pneumococcal bacteremia may be as high as $60 \%$ in the elderly demented patients ${ }^{[5]}$. In the late 1970s, it was estimated that 164,000 cases of sepsis occurred in the USA each year ${ }^{[6]}$. Another population-based recent analysis showed increased incidence of sepsis and septic shock from 13 to 78 cases per 100,000 from 1998 to $2001^{[7]}$. In an observational cohort study by stiermaier et al. ${ }^{[8]}, 28$-day mortality in patients with sepsis was found to be $29.5 \%$ and increased to $55.4 \%$ in 3 years after discharge from the hospital. The elderly are more predisposed to nosocomial infections and physical deconditioning when admitted to the acute care hospitals ${ }^{[0]}$. The elderly hospitalized patients with dementia are at high risk for urinary tract infection (UTI), pressure sores, pneumonia, and delirium ${ }^{[10,11]}$. This puts them at risk for bacteremia, which could accentuate mortality. The severity of disease appears to be increasing ${ }^{[12]}$. But mortality rate appears to have decreased in severe sepsis and septic shock after adjusting for age and comorbidities. This is due to increased adherence to severe sepsis and septic shock bundle ${ }^{[6,13]}$.

The elderly patients, especially women who have multiple comorbidities and also those with severe congestive heart failure $(\mathrm{CHF})$ (especially right heart failure) are at high risk for sepsis ${ }^{[14]}$. Also, the elderly with dementia have increased incidence of UTI, pressure sores, pneumonia, trauma, and delirium, which complicates the clinical scenario ${ }^{[10,15]}$. Pneumonia and indwelling catheter-related sepsis are the most common causes of secondary bacteremia ${ }^{[16]}$.

Diabetes, because of its high prevalence in the elderly, is the most common risk factor for sepsis. It also results in increased risk of nosocomial sepsis ${ }^{[17]}$. Pneumonia may predispose to severe sepsis in roughly half the patients and about $5 \%$ may go into septic shock ${ }^{[18]}$. Traveling may be a risk factor for sepsis irrespective of age and diarrhea is usually the most common cause when traveling to $\mathrm{Asia}^{[19]}$.

\section{PATHOPHYSIOLOGICAL BASIS OF CLINICAL SYMPTOMATOLOGY}

Cellular immunity in the elderly is hyperactive and humoral immunity is depressed ${ }^{[20,21]}$. So the elderly with sepsis may not show classical signs of sepsis, especially fever secondary to compromised humoral immunity ${ }^{[18]}$. Leukemoid reaction (LR) may be seen in sepsis and carries a grave prognosis in the elderly ${ }^{[22]}$. It is the comorbidities that often define the clinical presentation of the sepsis in the elderly ${ }^{[23]}$.

\section{PROGNOSTIC FACTORS}

Astute prognostication prior to aggressive management of the elderly in the critical care settings may decrease patient discomfort and reduce cost ${ }^{[24]}$. Prognostic factors are, especially important in the emergency and elective perioperative settings. According to American society of anesthesiologists, the most important prognosticators are functional status, sepsis, and age. In a study by Al-Temini et al., for the elderly aged more than 90 years with septic shock and poor preoperative functionality, the chances of survival were less than $10 \%{ }^{[25]}$. In the postoperative settings, the most common cause of death is CHF, sepsis, and multi-organ failure ${ }^{[26]}$. In a study by Lemay et al, the predictors of long-term mortality included CHF, PAD, $\mathrm{DM}$, and mechanical ventilation ${ }^{[17]}$. Age, comorbidities, length of stay (LOS), diagnosis of sepsis or malignancy are predictors of mortality at 6 months in the elderly discharged from the hospital ${ }^{[27]}$.

Comorbidities predict and define the prognosis. The site of infection in patients with sepsis may be an important determinant of outcome, with skin infections generally being associated with the lowest mortality rates ${ }^{[14]}$. Mortality in emergency department sepsis (MEDS) score and PCT increases the prognostication and risk stratification in the elderly with sepsis ${ }^{[28-32]}$. MEDS is based on cardiorespiratory, neurological, and hematological variables .Also, high points are added if there is an underlying terminal illness or the patient is institutionalized. MEDS scoring system helps in prediction of mortality in sepsis and could potentially help in astute prognostication and withholding treatment when clinically futile ${ }^{[30,33-36]}$.

\section{CLINICAL CONUNDRUMS AND CHALLENGES IN MANAGEMENT OF SEPSIS}

Substantial health care resources are spent in the terminal stages of life. Many of the treatment modalities are rather ineffective and costs huge amount of healthcare dollars. Majority of the patients with sepsis are the elderly and treated in the non-ICU settings ${ }^{[8]}$. The surviving sepsis campaign emphasizes two bundles of care. The initial bundle is focused on resuscitation to restore the impaired tissue perfusion and oxygenation ${ }^{[37]}$. This is to be accomplished in the first 6 hours of presentation. The second bundle is focused on further management and is to be accomplished in the ICU. Early diagnosis and goaldirected therapy is the goal ${ }^{[38,39]}$. The resuscitation requires the use of fluids and pressors. The kind of fluids and pressors remain a matter of debate. Protocolized approach in the implementation of these bundles is emphasized ${ }^{[40]}$. 
Use of ventilatory weaning and glycemic control protocols are classified as grade $1 \mathrm{~A}$ recommendations in the surviving sepsis campaign protocols ${ }^{[40]}$.

Although excellent, the surviving sepsis campaign guidelines are not very specific in the elderly with severe sepsis and septic shock. The elderly are very fragile and interference of one-body system may lead to dysfunction of other systems. Clinical conundrums that complicate clinical course of sepsis in the elderly need to be addressed (Ref Fig. 1).

The most common cause of hospitalization in the elderly in high income countries is $\mathrm{CHF}^{[14]}$. In a study by Alon et al., $38 \%$ of patients admitted for CHF had underlying sepsis with respiratory sepsis being most common. Urinary, skin, and soft tissue infections were other common entities ${ }^{[14]}$. Atrial fibrillation (AF) is also concomitantly present in patients with CHF. The tachycardia associated with sepsis may be wrongly attributed to AF and thereby delay the diagnosis and management of sepsis in the elderly. In a retrospective study by Walkey et al., age was one of the prime determinant of new onset and prevalence of $\mathrm{AF}$ in the elderly population. AF may be an underlying comorbidity or may be a manifestation of sepsis. Rate control and therapeutic anticoagulation potentially gets complicated with underlying sepsis. Anticoagulation with Coumadin is usually complicated because of the use of $\mathrm{CYH}$ inhibiting or stimulating medications in critical care settings. Also, if new oral anticoagulants are being used, their anticoagulant effect may be compromised or increased depending on drug interactions or changing renal function ${ }^{[3]}$. In these settings, it is better to use either unfractionated heparin or enoxaparin until the patient is stable. The surviving sepsis campaign offers no specific guidelines in the matter.

Hemodynamic changes in sepsis may predispose the elderly to acute kidney injury (AKI), especially if they have underlying chronic kidney disease $(\mathrm{CKD})^{[41]}$. Most common renal manifestation of sepsis is $\mathrm{AKI}^{[42]}$. In a study by Romao et al., sepsis in itself or in combination with other factors such as hypotension and nephrotoxic medications was responsible for AKI in the elderly ${ }^{[43]}$. These are potentially correctable in majority of the cases ${ }^{[4]}$. Sepsis-related AKI has been associated with increased mortality ${ }^{[4]}$. AKI that happens more than a week later into the postoperative period is usually a sign of sepsis in the elderly patients ${ }^{[46]}$. $\mathrm{CHF}$ and $\mathrm{CKD}$ are usually coexistent in the elderly population thus exacerbating the electrolyte imbalance. Fluid resuscitation in this population is critical but needs to be titrated carefully. Superadded insult of AKI needs to be avoided. Nephrotoxic agents should be avoided as the elderly in critical care settings are at high risk for $\mathrm{AKI}^{[41,47]}$. Failure to aggressively try to restore perfusion early may also be associated with mortality. On the other hand, aggressive hydration is likely to lead to CHF and respiratory failure in the elderly who often have underlying CHF. Although critical, surviving sepsis campaign offers no specific guidelines for renal protection.

Delirium and dementia are often made worse in the critical care settings. Polypharmacy and potentially inappropriate medication use is one of the major contributor to delirium in the hospitalized the elderly ${ }^{[48]}$. The elderly are more predisposed to depression and alcohol abuse. Delirium may be a manifestation of underlying sepsis in the elderly, especially when the patient is in long-term care setting. This may present as a diagnostic challenge to the clinician ${ }^{[38,49-51]}$. The clinical picture of delirium may be complicated by the use of sedative drug use, post-operative state, and ambulatory dysfunction ${ }^{[48,52,53]}$. Often, they are on polypharmacy, which opens the door for drug-induced delirium ${ }^{[54]}$. This may further pose a challenge in management of sepsis. Often, diagnosis of sepsis may be missed because of the masking effect of the comorbidities ${ }^{[2,41]}$. The elderly with delirium have more complications related to hospitalization than patients without delirium ${ }^{[10,55]}$. Delirium predisposes the elderly to high risk for peripheral muscle wasting and consequent ambulatory dysfunction ${ }^{[5]}$. This reinforces the need to minimize polypharmacy and potentially inappropriate medication use in the elderly. Again, the surviving sepsis campaign surprisingly falls short on guidelines on this aspect of sepsis management.

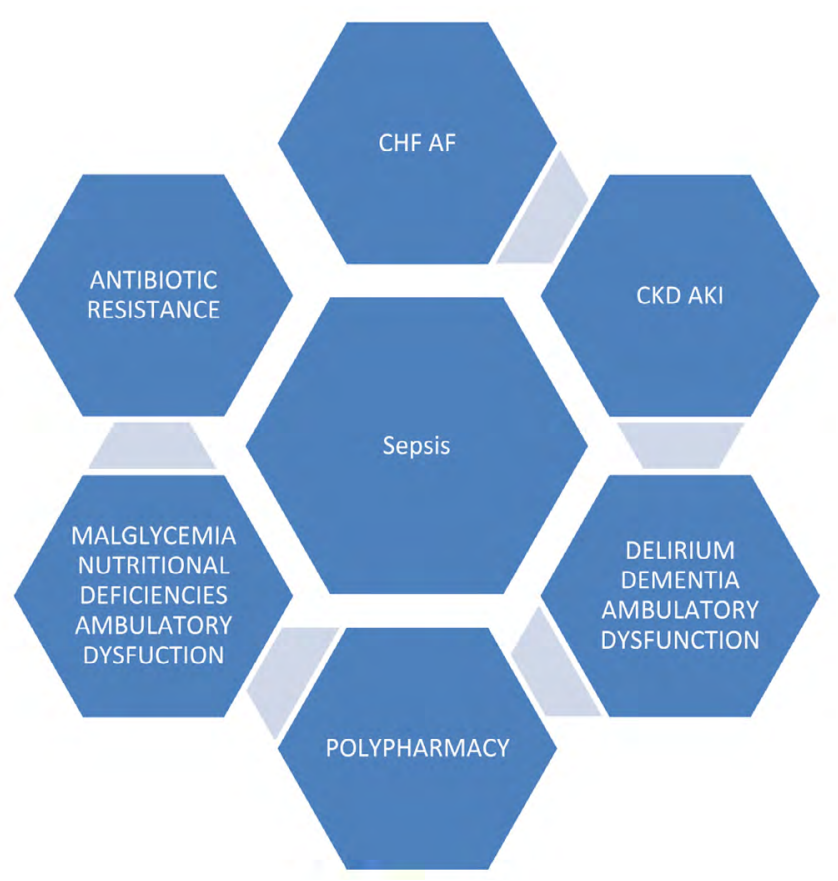

Figure 1: Clinical conundrums in management of sepsis in the elderly. 
Hypoglycemia is commonly seen in the elderly with CKD and sepsis and usually indicates a bad prognosis ${ }^{[4,57-59]}$. This may be seen in both diabetics and non diabetics ${ }^{[8,57,60-62]}$. This is due to decreased metabolism of insulin and diminished glycogen reserves in the body. Intensive insulin regime should be discouraged in the critical care settings with target glucose levels less than 180 but more than $120 \mathrm{mg} \%$. Malnutrition in the hospitalized elderly could contribute to hypoglycemia and may be related to shortterm mortality ${ }^{[63-64]}$. Enteral feeding should be started within 48 hours when feasible. Total parenteral (TPN) feeding could be considered when enteral feeding is not possible. Structured lipid emulsions for TPN in sepsis are considered more effective ${ }^{[6]}$. Anemia of chronic disease is also a result of sepsis and manifests secondary to altered iron metabolism ${ }^{[6]}$. Underlying sick euthyroid syndrome indicates a worse outcome $e^{[23,67]}$.

Ambulatory dysfunction is another clinical conundrum, which could potentially complicate the treatment and increase the length of stay. It further predisposes to nosocomial infections. More often than not, they need inpatient rehabilitation prior to discharge to home. So physical therapy and early ambulation needs to be prioritized $^{[27]}$.

The clinical conundrum of antibiotic resistance has significant impact on morbidity and mortality in the elderly and needs to be considered when starting antibiotics in the elderly ${ }^{[68]}$. In September 2013, antibiotic resistance report by Center for Disease Control and Prevention (CDC) reported that majority of antibiotic resistance-related deaths occur in healthcare settings like nursing homes, long-term acute care or acute care hospitals where bulk of the patients are elderly and exposed to repeated antibiotics (Table 1). As per CDC, about 2 million patients are sickened each year in USA by infections that are resistant to antibiotics. About 23,000 people die each year secondary to antibiotic resistance and failure of treatment. In 2008, Roberts et al., studied the cost attributable to antibiotic resistance in 188 hospitalized patients. By conservative estimates, the cost was estimated to be 13.35 million dollars ${ }^{[69]}$.

The CDC has defined three levels of threats posed by antibiotic resistance. The threats have been classified as urgent, serious, or concerning depending on the urgency and gravity of the situation (Tab. 1). In the urgent category is Clostridium difficile-associated diarrhea (CDAD), which is directly linked to widespread and inappropriate antibiotic use in the elderly population ${ }^{[70]}$. There are not many antimicrobial agents available to treat $\mathrm{CDAD}$ and the prevalence of CDAD continues to increase. Fidaxomicin is a relatively new macrolide to treat the CDAD. It is considered a first-line drug in the treatment of recurrent
CDAD. It has minimal effect on the gut microflora and persists in the bowels for at least 21 days $^{[1-73]}$. It is associated with fewer recurrences and sustained clinical cure $^{[74-78]}$. It has favorable pharmacokinetics and minimal drug interactions. But it needs to be used with caution to prevent drug resistance. Methicillin-resistant Staphylococcus aureus (MRSA) and drug-resistant streptococcal pneumonia figure in the serious category in antibiotic resistance threat report by the CDC. MRSA causes 80,000 cases of severe infections each year and 11,000 deaths occur each year in USA. Although these microbes commonly afflict the elderly, they are not classified as urgent due to more antibiotics available for clinical use in this category. Multidrug-resistant (MDR) pseudomonas also figures in the list of serious threat. Antibiotics may be used with cynicism at times as excess may not always be good. Dual antibiotics with quinolones may not be needed in all patients with pseudomonas pneumonia ${ }^{[79]}$.

On the other hand, inadequate antibiotics may be associated with increased mortality in the elderly ${ }^{[0,81]}$. Sepsis due to nosocomial pathogens has a higher mortality than sepsis due to community-acquired pathogens. With HCAI, there are increased chances of inadequate antibiotic use. In contrast, prior antibiotic therapy may be associated with increased mortality, at least among patients with Gramnegative sepsis. With high incidence of readmissions to the hospital, there is increasing incidence of HCAI and increasing microbial resistance ${ }^{[81]}$. This is because patients who have received prior antibiotic therapy are more likely to have higher rates of antibiotic resistance, making it less likely that appropriate antibiotic therapy will be chosen empirically. PCT-guided antibiotics have shown to decrease the duration of antibiotics ${ }^{[13]}$. There is increased resistance to B lactams for pneumococcus. Increase in PCT $>9$ suggests severe sepsis and increase in mortality and morbidity. PCT has also been used for severity classification and treatment decisions in sepsis ${ }^{[13,30]}$.

\begin{tabular}{|c|c|}
\hline URGENT & $\begin{array}{l}\text { C. difficile, carbepenem-resistant } \\
\text { enteriobacteriacea, drug-resistant Neisseria } \\
\text { gonorrhea }\end{array}$ \\
\hline SERIOUS & $\begin{array}{l}\text { Multidrug-resistant acinetobacter, drug- } \\
\text { resistant campylobacter, fluconazole-resistant } \\
\text { candida, extended spectrum beta lactamase, } \\
\text { vancomycin-resistant enterococcus, MDR } \\
\text { pseudomonas, drug-resistant non-typhi } \\
\text { salmonella, drug-resistant salmonella typhi, } \\
\text { MRSA, drug-resistant streptococcal pneumonia, } \\
\text { drug-resistant tuberculosis }\end{array}$ \\
\hline CONCERNING & $\begin{array}{l}\text { Vancomycin-resistant } S \text {. aureus, erythromycin- } \\
\text { resistant group A Strep, clindamycin-resistant } \\
\text { group B streptococcus. }\end{array}$ \\
\hline
\end{tabular}

Adapted from September 2013 CDC report on antimicrobial resistance. 
CDC is working on modules to track the antibiotic resistance in hospital labs. It would be compiled in national data base and made available to local and state authorities that could track the data further and make corrective steps to minimize antibiotic resistance. Also, this needs to go hand in hand with antibiotic stewardship, which ensures appropriate use of antibiotics. CDC estimates that more than half the people who get antibiotics do not really need it. Antibiotic development has not kept pace with rapidity with which antibiotic resistance has been developing and that is a reason for concern. Future research should focus not only on developing antibiotics but also biological therapy for infectious diseases. The avenue to treat bacterial infections with biologic approach has been a success story in some areas. Fecal transplant to treat recurrent CDAD holds promise ${ }^{[82]}$. It needs some improvisation for wide acceptance by the physicians and the patient population.

Vaccine for pneumococcal pneumonia has been a success story. It has shown to reduce hospitalization for pneumonia by reducing the incidence of invasive disease ${ }^{[83]}$. High potency influenza vaccine has shown promise in the elderly in prevention of influenza ${ }^{[84]}$. Vaccines for $S$. aureus are not effective so far. Continued research is needed in this direction to lower the burden of infectious disease.

\section{CONCLUSION}

Diagnosis and treatment of sepsis in the elderly is a rigmarole of complex clinical conundrums. The presentation is often atypical. They frequently have multiple comorbidities, which define the presentation and prognosis of sepsis in the elderly. The need of the hour are guidelines that emphasize the management of clinical conundrums associated with sepsis in the elderly. This would not only be cost effective but improve the morbidity, mortality, and quality of life in the elderly.

\section{Conflicts of Interest}

None declared.

\section{REFERENCES}

1. Levy MM, Fink MP, Marshall JC, Abraham E, Angus D, Cook D, et al. 2001 SCCM/ESICM/ACCP/ATS/SIS International Sepsis Definitions Conference. Intensive Care Med 2003;29:530-8.

2. Starr ME, Saito H. Sepsis in old age: review of human and animal studies. Aging Dis 2014;5:126-36.

3. Sehgal V, Bajwa SJ, Bajaj A. New orally active anticoagulants in critical care and anesthesia practice: The good, the bad and the ugly. Ann Card Anaesth 2013;16:193-200.

4. Kalra BS. Cytochrome P450 enzyme isoforms and their therapeutic implications: an update. Indian J Med Sci 2007;61:102-16.

5. Deulofeu F, Cervelló B, Capell S, Martí C, Mercadé V. Predictors of mortality in patients with bacteremia: the importance of functional status. J
Am Geriatr Soc 1998;46:14-8.

6. Martin GS, Mannino DM, Eaton S, Moss M. The epidemiology of sepsis in the United States from 1979 through 2000. N Engl J Med 2003;348:154654.

7. Walkey AJ, Wiener RS, Lindenauer PK. Utilization patterns and outcomes associated with central venous catheter in septic shock: a populationbased study. Crit Care Med 2013;41:1450-7.

8. Stiermaier T, Herkner H, Tobudic S, Burgmann K, Staudinger T, Schellongowski $\mathrm{P}$, et al. Incidence and long-term outcome of sepsis on general wards and in an ICU at the General Hospital of Vienna: an observational cohort study. Wien Klin Wochenschr 2013;125:302-8.

9. Lim SC, Doshi V, Castasus B, Lim JK, Mamun K. Factors causing delay in discharge of elderly patients in an acute care hospital. Ann Acad Med Singapore 2006;35:27-32.

10. Bail K, Berry H, Grealish L, Draper B, Karmel R, Gibson D, et al. Potentially preventable complications of urinary tract infections, pressure areas, pneumonia, and delirium in hospitalised dementia patients: retrospective cohort study. BMJ Open 2013;3:e002770.

11. Eliason D. It may not be "a little dementia". MLO Med Lab Obs 2011;43:9.

12. Whittaker SA, Mikkelsen ME, Gaieski DF, Koshy S, Kean C, Fuchs BD. Severe sepsis cohorts derived from claims-based strategies appear to be biased toward a more severely ill patient population. Crit Care Med 2013;41:945-53.

13. Hohn A, Schroeder S, Gehrt A, Bernhardt K, Bein B, Wegscheider K, et al. Procalcitonin-guided algorithm to reduce length of antibiotic therapy in patients with severe sepsis and septic shock. BMC Infect Dis 2013;13:158.

14. Alon D, Stein GY, Korenfeld R, Fuchs S. Predictors and outcomes of infection-related hospital admissions of heart failure patients. PLoS One 2013;8:e72476.

15. Kahl JE, Calvo RY, Sise MJ, Sise CB, Thorndike JF, Shackford SR. The changing nature of death on the trauma service. J Trauma Acute Care Surg 2013;75:195-201.

16. Lee A, Lau TN, Yeong KY. Indwelling catheters for the management of malignant ascites. Support Care Cancer 2000;8:493-9.

17. Lemay AC, Anzueto A, Restrepo MI, Mortensen EM. Predictors of long-term mortality after severe sepsis in the elderly. Am J Med Sci 2014; 347:282-8.

18. Wester AL, Dunlop O, Melby KK, Dahle UR, Wyller TB. Age-related differences in symptoms, diagnosis and prognosis of bacteremia. BMC Infect Dis 2013;13:346.

19. Alon D, Shitrit P, Chowers M. Risk behaviors and spectrum of diseases among elderly travelers: a comparison of younger and older adults. J Travel Med 2010;17:250-5.

20. Iakubtsevich RE, Spas VV, Dorokhin KM. [Clinical course and intensive therapy of sepsis in geriatric patients]. Klin Med (Mosk) 2003;81:28-32.

21. Zhou M, Wu R, Dong W, Leong J, Wang P. Accelerated apoptosis contributes to aging-related hyperinflammation in endotoxemia. Int J Mol Med 2010;25:929-35.

22. Potasman I, Grupper M. Leukemoid reaction: spectrum and prognosis of 173 adult patients. Clin Infect Dis 2013;57:e177-81.

23. Sehgal V, Bajwa SJ, Sehgal R, Bajaj A. Clinical Conundrums in Management of Hypothyroidism in Critically Ill Geriatric Patients. Int J Endocrinol Metab 2014;12:e13759.

24. Sacanella E, Pérez-Castejón JM, Nicolás JM, Masanés F, Navarro M, Castro P, et al. Functional status and quality of life 12 months after discharge from a medical ICU in healthy elderly patients: a prospective observational study. Crit Care 2011;15:R105.

25. Al-Temimi MH, Griffee M, Enniss TM, Preston R, Vargo D, Overton S, et al. When is death inevitable after emergency laparotomy? Analysis of the American College of Surgeons National Surgical Quality Improvement Program database. J Am Coll Surg 2012;215:503-11.

26. Andriescu L, Patraşcanu E, Dănilă R, Bădic B, Rădulescu C. [Acute surgical pathology in elderly patients]. Rev Med Chir Soc Med Nat Iasi 2005;109:286-9. 
27. Baldwin MR, Narain WR, Wunsch H, Schluger NW, Cooke JT, Maurer MS, et al. A prognostic model for 6-month mortality in elderly survivors of critical illness. Chest 2013;143:910-9.

28. Liu YJ, Du P, Rao J. Procalcitonin as a diagnostic and prognostic marker for sepsis caused by intestinal infection: a case report. Eur Rev Med Pharmacol Sci 2013;17:1311-3.

29. Magrini L, Travaglino F, Marino R, Ferri E, De Berardinis B, Cardelli P, et al. Procalcitonin variations after Emergency Department admission are highly predictive of hospital mortality in patients with acute infectious diseases. Eur Rev Med Pharmacol Sci 2013;17 Suppl 1:133-42.

30. Park JH, Wee JH, Choi SP, Park KN. Serum procalcitonin level for the prediction of severity in women with acute pyelonephritis in the ED: value of procalcitonin in acute pyelonephritis. Am J Emerg Med 2013;31:1092-7.

31. Stucker F, Herrmann F, Graf JD, Michel JP, Krause KH, Gavazzi G. Procalcitonin and infection in elderly patients. J Am Geriatr Soc 2005;53:1392-5.

32. Zhao Y, Li C, Jia Y. Evaluation of the Mortality in Emergency Department Sepsis score combined with procalcitonin in septic patients. Am J Emerg Med 2013;31:1086-91.

33. Jeong SJ, Yoon SS, Han SH, Yong DE, Kim CO, Kim JM. Evaluation of humoral immune response to nosocomial pathogen and functional status in elderly patients with sepsis. Arch Gerontol Geriatr 2014; 58:10-4.

34. Chen YX, Li CS. Prognostic value of adrenomedullin in septic patients in the ED. Am J Emerg Med 2013;31:1017-21.

35. Kuo SH, Lee YT, Li CR, Tseng CJ, Chao WN, Wang PH, et al. Mortality in Emergency Department Sepsis score as a prognostic indicator in patients with pyogenic liver abscess. Am J Emerg Med 2013;31:916-21.

36. Shapiro NI, Wolfe RE, Moore RB, Smith E, Burdick E, Bates DW. Mortality in Emergency Department Sepsis (MEDS) score: a prospectively derived and validated clinical prediction rule. Crit Care Med 2003;31:670-5.

37. Angus DC, van der Poll T. Severe sepsis and septic shock. N Engl J Med. 2013;369:840-51.

38. Arinzon Z, Peisakh A, Schrire S, Berner YN. Delirium in long-term care setting: indicator to severe morbidity. Arch Gerontol Geriatr 2011;52:2705.

39. Miller RR 3rd, Dong L, Nelson NC, Brown SM, Kuttler KG, Probst DR, et al. Multicenter implementation of a severe sepsis and septic shock treatment bundle. Am J Respir Crit Care Med 2013;188:77-82.

40. Dellinger RP, Levy MM, Rhodes A, Annane D, Gerlach H, Opal SM, et al. Surviving sepsis campaign: international guidelines for management of severe sepsis and septic shock: 2012. Crit Care Med 2013;41:580-637.

41. Chronopoulos A, Cruz DN, Ronco C. Hospital-acquired acute kidney injury in the elderly. Nat Rev Nephrol 2010;6:141-9.

42. Shah PR, Gireesh MS, Kute VB, Vanikar AV, Gumber MR, Patel HV, et al. Renal involvement in sepsis: a prospective single-center study of 136 cases. Saudi J Kidney Dis Transpl 2013;24:620-9.

43. Romão Junior JE, Haiashi AR, Vidonho Junior AF, Abensur H, Quintaes PS, Araújo MR, et al. [Causes and prognosis of acute renal failure in elderly patients]. Rev Assoc Med Bras 2000;46:212-7.

44. Khurana V, Gambhir IS, Kishore D. Evaluation of delirium in elderly: a hospital-based study. Geriatr Gerontol Int 2011;11:467-3.

45. Moore EM, Bellomo R, Nichol AD. The meaning of acute kidney injury and its relevance to intensive care and anaesthesia. Anaesth Intensive Care 2012;40:929-48.

46. Hoste EA, Kellum JA, Katz NM, Rosner MH, Haase M, Ronco C. Epidemiology of acute kidney injury. Contrib Nephrol 2010;165:1-8.

47. Bagshaw SM, Bellomo R, Kellum JA. Oliguria, volume overload, and loop diuretics. Crit Care Med 2008;36(4 Suppl):S172-8.

48. Sehgal V, Bajwa SJ, Sehgal R, Bajaj A, Khaira U, Kresse V. Polypharmacy and potentially inappropriate medication use as the precipitating factor in readmissions to the hospital. J Family Med Prim Care 2013;2:194-9.

49. Collopy KT, Kivlehan S, Snyder SR. Acute altered mental status in elderly patients: what can cause geriatric AMS and delirium? EMS World 2013;42:31-9.
50. Luitse MJ, van Asch CJ, Klijn CJ. Deep coma and diffuse white matter abnormalities caused by sepsis-associated encephalopathy. Lancet 2013;381:2222.

51. Rutten S, Schadé A. [Atypical presentation of delirium: risk of misdiagnosis and undertreatment]. Ned Tijdschr Geneeskd 2013;157:A5910.

52. Isfandiaty R, Harimurti K, Setiati S, Roosheroe AG. Incidence and predictors for delirium in hospitalized elderly patients: a retrospective cohort study. Acta Med Indones 2012;44:290-7.

53. Gunther ML, Morandi A, Ely EW. Pathophysiology of delirium in the intensive care unit. Crit Care Clin 2008;24:45-65, viii.

54. Sehgal V, Bajwa SS, Khaira U, Sehgal R, Bajaj A. Challenging aspects of and solutions to diagnosis, prevention, and management of hypoglycemia in critically ill geriatric patients. J Sci Soc 2013;40:128-34.

55. Rubenfeld GD. Does the hospital make you older faster? Am J Respir Crit Care Med 2012;185:796-8.

56. Baldwin CE, Bersten AD. Alterations in respiratory and limb muscle strength and size in patients with sepsis who are mechanically ventilated. Phys Ther 2014;94:68-82.

57. Sehgal V, Jit Singh Bajwa S, Kitabchi A. Coronary artery bypass grafting: a precipitating factor for perioperative diabetic ketoacidosis. Int J Endocrinol Metab 2013;11:126-8.

58. Kagansky N, Levy S, Rimon E, Cojocaru L, Fridman A, Ozer Z, et al. Hypoglycemia as a predictor of mortality in hospitalized elderly patients. Arch Intern Med 2003;163:1825-9.

59. Suaya JA, Eisenberg DF, Fang C, Miller LG. Skin and soft tissue infections and associated complications among commercially insured patients aged 0-64 years with and without diabetes in the U.S. PLoS One 2013;8:e60057.

60. Mendoza A, Kim YN, Chernoff A. Hypoglycemia in hospitalized adult patients without diabetes. Endocr Pract 2005;11:91-6.

61. Shilo S, Berezovsky S, Friedlander Y, Sonnenblick M. Hypoglycemia in hospitalized nondiabetic older patients. J Am Geriatr Soc 1998;46:978-82.

62. Storey S, Von Ah D. Impact of malglycemia on clinical outcomes in hospitalized patients with cancer: a review of the literature. Oncol Nurs Forum 2012;39:458-65.

63. Lee JS, Choi HS, Ko YG, Yun DH. Performance of the Geriatric Nutritional Risk Index in predicting 28-day hospital mortality in older adult patients with sepsis. Clin Nutr 2013;32:843-8.

64. Kagansky N, Levy S, Koren-Morag N, Berger D, Knobler H. Hypophosphataemia in old patients is associated with the refeeding syndrome and reduced survival. J Intern Med 2005;257:461-8.

65. Chen J, Yan J, Cai GL, Xu QH, Gong SJ, Dai HW, et al. Structured lipid emulsion as nutritional therapy for the elderly patients with severe sepsis. Chin Med J (Engl). 2013;126:2329-32.

66. Piagnerelli M, Cotton F, Herpain A, Rapotec A, Chatti R, Gulbis B. Time course of iron metabolism in critically ill patients. Acta Clin Belg. 2013;68:22-7.

67. Meyer S, Schuetz P, Wieland M, Nusbaumer C, Mueller B, Christ-Crain $\mathrm{M}$. Low triiodothyronine syndrome: a prognostic marker for outcome in sepsis? Endocrine 2011;39:167-74.

68. Butler MS, Blaskovich MA, Cooper MA. Antibiotics in the clinical pipeline in 2013. J Antibiot (Tokyo) 2013;66:571-91.

69. Roberts RR, Hota B, Ahmad I, Scott RD 2nd, Foster SD, Abbasi F, et al. Hospital and societal costs of antimicrobial-resistant infections in a Chicago teaching hospital: implications for antibiotic stewardship. Clin Infect Dis 2009;49:1175-84.

70. Weis S, John E, Lippmann N, Mössner J, Lübbert C. [Clostridium difficile Infection (CDI) in the Course of Time - An Issue Only for the Internist?]. Zentralbl Chir 2014;139:460-8.

71. Chilton CH, Crowther GS, Freeman J, Todhunter SL, Nicholson S, Longshaw CM, et al. Successful treatment of simulated Clostridium difficile infection in a human gut model by fidaxomicin first line and after vancomycin or metronidazole failure. J Antimicrob Chemother 2014;69:451-62

72. Green MR, Acharya UH, Yeager AM. Is Fidaxomicin the Drug of Choice for Treating Clostridium difficile-Associated Diarrhea in Patients With Cancer? J Clin Oncol 2013; 31:4376-8. 
73. Sears P, Ichikawa Y, Ruiz N, Gorbach S. Advances in the treatment of Clostridium difficile with fidaxomicin: a narrow spectrum antibiotic. Ann N Y Acad Sci 2013;1291:33-41.

74. Chaparro-Rojas F, Mullane KM. Emerging therapies for Clostridium difficile infection - focus on fidaxomicin. Infect Drug Resist 2013;6:41-53.

75. Juang P, Hardesty JS. Role of fidaxomicin for the treatment of clostridium difficile infection. J Pharm Pract 2013;26:491-7.

76. Mullane KM, Cornely OA, Crook DW, Golan Y, Louie TJ, Miller MA, et al. Renal impairment and clinical outcomes of Clostridium difficile infection in two randomized trials. Am J Nephrol 2013;38:1-11.

77. Scott LJ. Fidaxomicin: A Review of Its Use in Patients with Clostridium difficile Infection. Drugs 2013;73:1733-47.

78. Soriano MM, Liao S, Danziger LH. Fidaxomicin: a minimally absorbed macrocyclic antibiotic for the treatment of Clostridium difficile infections. Expert Rev Anti Infect Ther 2013;11:767-76.

79. Planquette B, Timsit JF, Misset BY, Schwebel C, Azoulay E, Adrie C, et al. Pseudomonas aeruginosa ventilator-associated pneumonia. predictive factors of treatment failure. Am J Respir Crit Care Med 2013;188:69-76.

80. Schechner V, Gottesman T, Schwartz O, Korem M, Maor Y, Rahav G, et al. Pseudomonas aeruginosa bacteremia upon hospital admission: risk factors for mortality and influence of inadequate empirical antimicrobial therapy. Diagn Microbiol Infect Dis 2011;71:38-45.

81. Cardoso T, Ribeiro O, Aragão I, Costa-Pereira A, Sarmento A. The impact of healthcare-associated infection on mortality: failure in clinical recognition is related with inadequate antibiotic therapy. PLoS One 2013;8:e58418.

82. Mondot S, de Wouters T, Doré J, Lepage P. The human gut microbiome and its dysfunctions. Dig Dis 2013;31:278-85.

83. Griffin MR, Zhu Y, Moore MR, Whitney CG, Grijalva CG. U.S. hospitalizations for pneumonia after a decade of pneumococcal vaccination. N Engl J Med 2013;369:155-63.

84. DiazGranados CA, Dunning AJ, Jordanov E, Landolfi V, Denis M, Talbot HK. High-dose trivalent influenza vaccine compared to standard dose vaccine in elderly adults: safety, immunogenicity and relative efficacy during the 2009-2010 season. Vaccine 2013;31:861-6.

How to cite this article: Sehgal et al. Clinical conundrums in management of sepsis in the elderly. J Transl Intern Med 2015;3:106112 